\title{
REVIEW OF ATTITUDES AND AWARENESS IN THE AGRICULTURAL INDUSTRY TO DIFFUSE POLLUTION ISSUES
}

Dave Merrilees and Alistair Duncan,

\author{
SAC Environmental, The Scottish Agricultural College, Auchincruive, Ayr KA6 5HW
}

E.mail D.Merrilees@au.sac.ac.uk

\begin{abstract}
The Scottish Executive considered that 'Diffuse Pollution from Agricultural Enterprises' was a priority issue for Scottish agriculture over the next 5-10 years and highlighted the need to improve knowledge transfer, advice and training through continued technical and professional development amongst farmers, crofters, contractors and advisers. In response to this report, The Scottish Environment Protection Agency commissioned SAC to survey advisory staff on their views on diffuse pollution issues, mitigation measures and delivery of environmental advice to the farming industry. The survey responses indicate that the impact of agricultural diffuse pollution on the environment is considered to be a serious problem as is the future impact of legislation on the farm business. To facilitate the rate of knowledge transfer to the industry there is an urgent requirement to raise advisers' awareness of environmental legislation and mitigation measures to reduce diffuse pollution. Advisers consider that farmers have limited awareness of diffuse pollution problems but those that do would consider the impact on the environment to be serious. Although advice is given by many advisers on pollution mitigation measures, there is a lack of knowledge on the effectiveness of these measures. Better technical information, supported by research, is required. This information is best conveyed to advisers via the internet, technical notes and directly by environmental specialists and delivered on to farmers by farm visits. Lack of funds prevent most farmers adopting best management practices to reduce diffuse pollution and more than $80 \%$ of advisers consider that environmental advice should be free.
\end{abstract}

Keywords: Advisory, agriculture, environment, legislation, pollution, training.

\section{INTRODUCTION}

The Scottish Executive, Agriculture and Environment Working Group considered that 'Diffuse Pollution from Agricultural Enterprises' was a priority issue for Scottish agriculture over the next 5-10 years. The report also highlighted the need to improve knowledge transfer, advice and training through continued technical and professional development amongst farmers, crofters, contractors and advisers.

In response to this report, The Scottish Environment Protection Agency (SEPA) commissioned the Scottish Agricultural College (SAC) to survey advisory staff in SAC, SEPA and Farming Wildlife Advisory Group (FWAG) on their views on diffuse pollution issues, mitigation measures and delivery of environmental advice to the farming industry. This survey is a fore-runner to a wider industry survey.

Their views will help facilitate delivery of Best Management Practices (BMP's) to the farming industry and provide a benchwork for tracking future changes in attitudes and awareness of diffuse pollution issues.

The Questionnaire was posted on the internet at http://www.heartlandenvironmental.co.uk/survey.htm and made available to respondents between 4 November and 13 December 2002.

\section{METHODS}

The views of agricultural advisers on the attitudes and awareness in the agricultural industry to diffuse pollution issues were collected by internet questionnaire to 130 advisers in SAC, SEPA and FWAG.

Having developed the technical content of the Questionnaire the questions were then assessed by independent specialists and amended to remove any bias or dubiety. The Questionnaire was structured in four sections:

Section 1: $\quad$ Awareness of Diffuse Pollution Problems.

Section 2: $\quad$ Rating of Diffuse Pollution Problems and Mitigation Measures.

Section 3: $\quad$ Training Requirements.

Section 4: $\quad$ Knowledge Transfer Mechanis ms.

Plus: General Comments.

The Questionnaire was compiled and the questions worded so that the review of attitudes and awareness to diffuse pollution issues could be assessed on other advisory groups and in future to the same advisory groups. This would allow changes in attitudes and awareness to be appraised and impacts of knowledge transfer to be assessed.

The target groups were sent a cover letter explaining the background and remit of the study along with details on how to access the Questionnaire on the internet http://www.heartland environmental.co.uk/survey.htm. The Questionnaire could 
only be accessed with the password provided. Individual responses were appended to an access data base on the SAC server and imported into EXCEL for analysis. There was a recommendation to advisers to complete the Questionnaire but there was no specific directive by any of the organisation to do so. A total of $80(62 \%)$ staff completed the Questionnaire and provided additional comment on the issues raised. The summary report was made available to all respondents on the web-site.

\section{RESULTS AND DISCUSSION}

\section{Awareness of Diffuse Pollution Problems}

1. Do you understand the term 'Diffuse Pollution'?

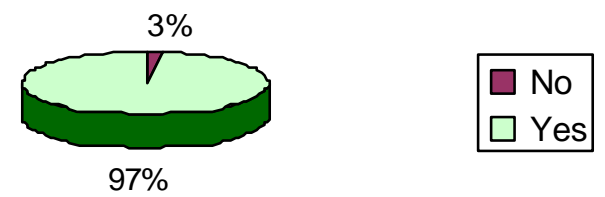

- $97 \%$ of all respondents understand the term 'Diffuse Pollution' but $11 \%$ could not provide an acceptable definition of the problem.

2. How would you describe the impact on the environment of diffuse pollution from agriculture?

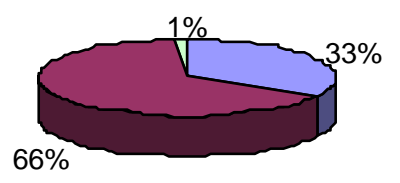

$\square$ A serious problem
$\square$ Of some concern
$\square$ No problem

- All respondents described the impact on the environment 'of some concern' or 'a serious

3. How would you describe the impact on the farm business of environmental legislation?

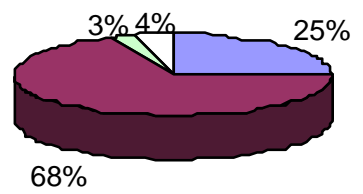

$\square$ A serious problem
$\square$ Of some concern
$\square$ No problem
$\square$ Don't know

- $94 \%$ of respondents described the impact of legislation on the farm business 'of some concern' or 'a serious problem'.

4. Are you aware of the requirements of the following legislation and their impacts on farming practice?

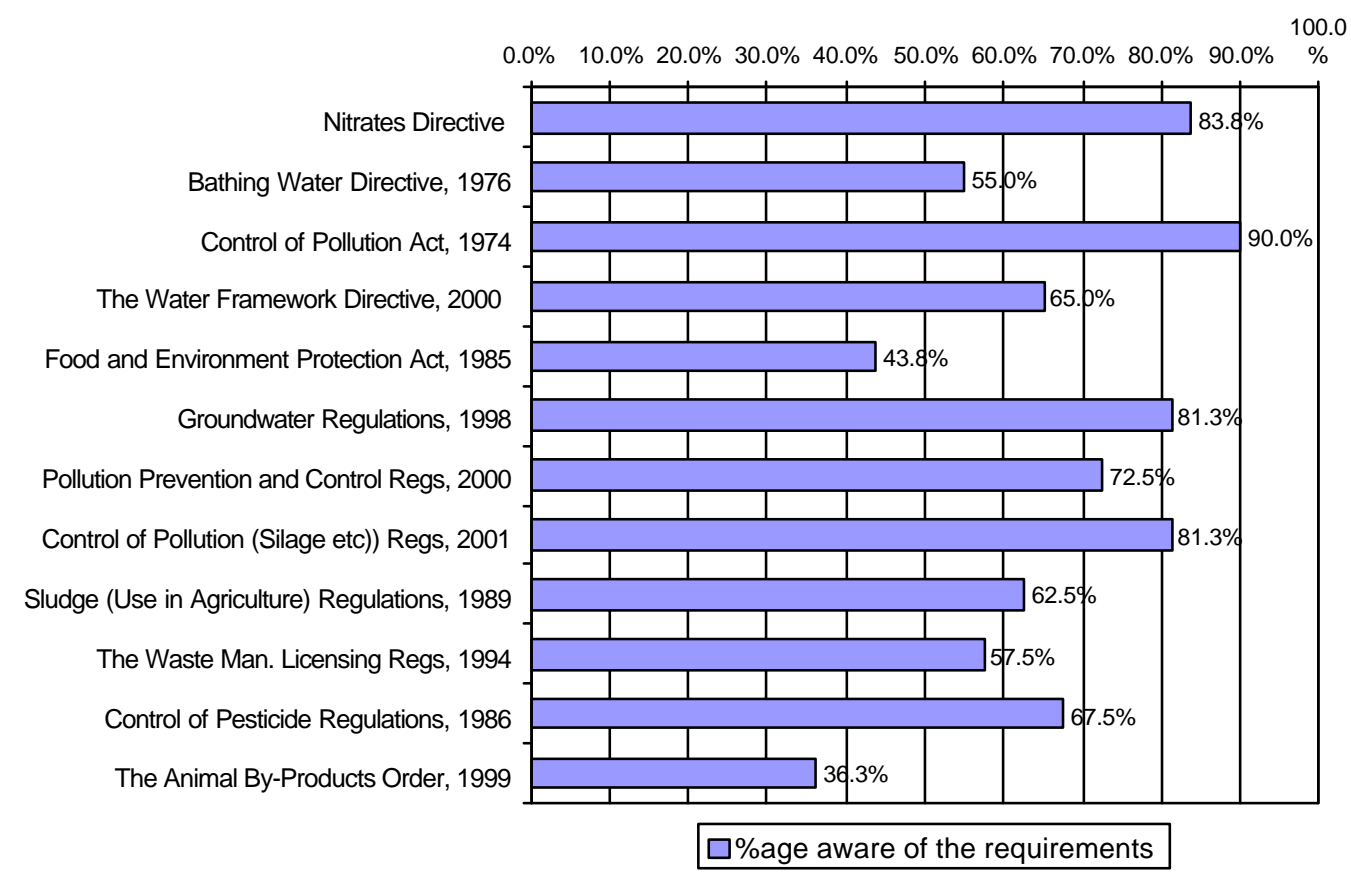

- There is a priority requirement to raise advisers' awareness of The Animal By -Products Order, Food and Environment Protection Act, Bathing Water Directive, The Waste Management Licensing Regulations. 
5. Have you a working knowledge of the advice given in the following?

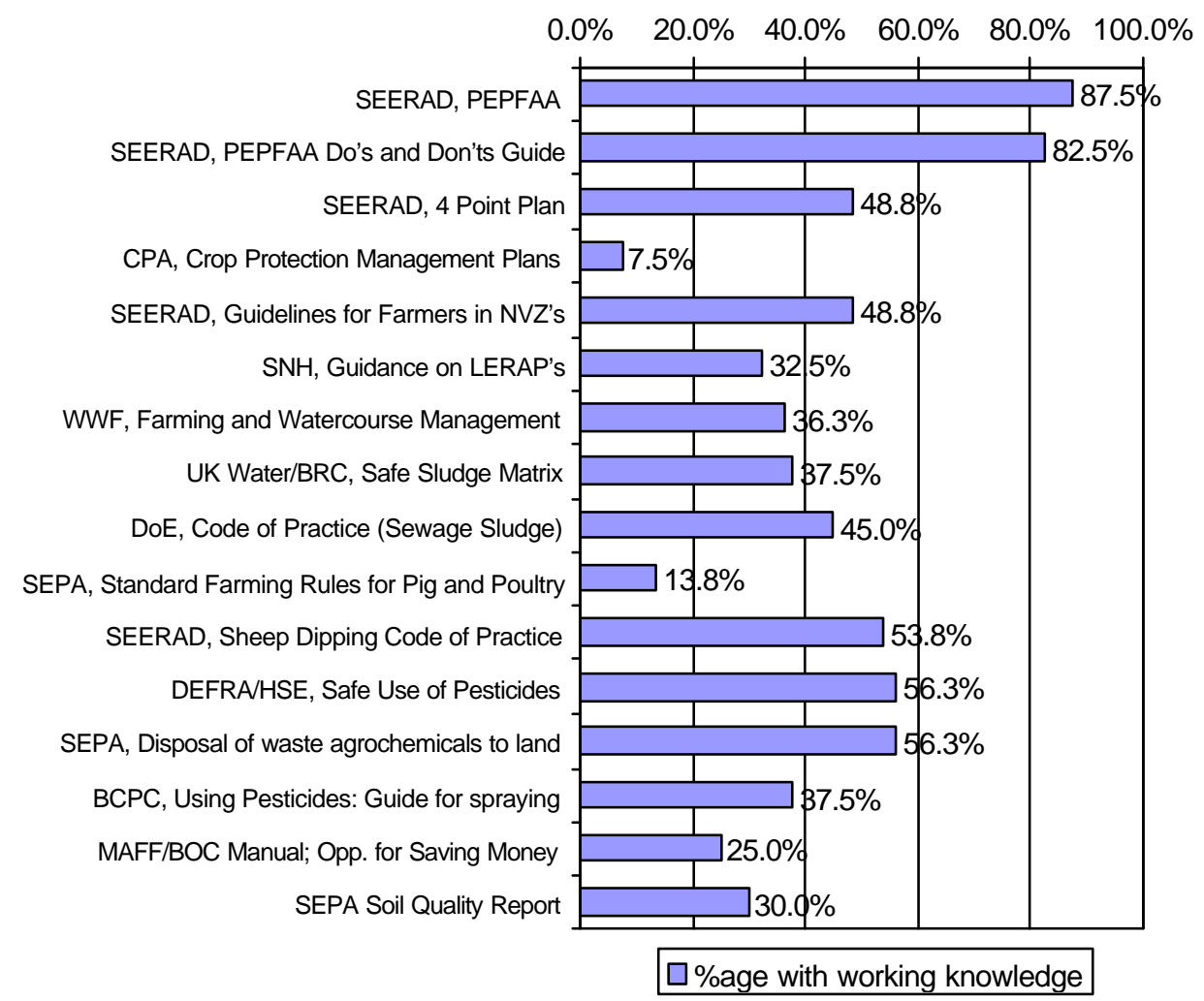

- There is an urgent requirement to improve advisers awareness of most Guidance documents to facilitate the rate of knowledge transfer to the industry.

6. In your opinion, are Farmers aware of 'Diffuse Pollution' problems?
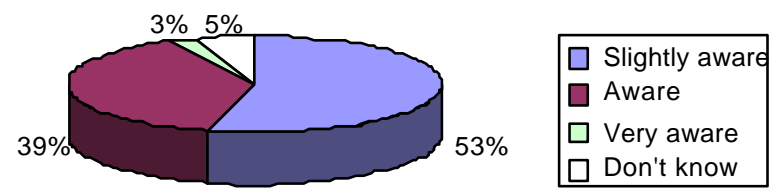

- Respondents indicate that farmers have limited awareness of 'Diffuse Pollution' problems.

7. In your opinion, how would Farmers describe the impact on the environment of diffuse pollution from agriculture?

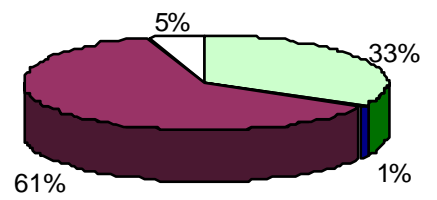

\begin{tabular}{|l|}
\hline No problem \\
$\square$ Of some concern \\
$\square$ Serious \\
$\square$ Don't know \\
\hline
\end{tabular}

- Majority $(61 \%)$ opinion is that farmers would consider the impact of diffuse pollution in the environment to be serious. 


\section{Rating of Diffuse Pollution Problems and Mitigation Measures}

8. How would you score the environmental impact of the following pollutants?

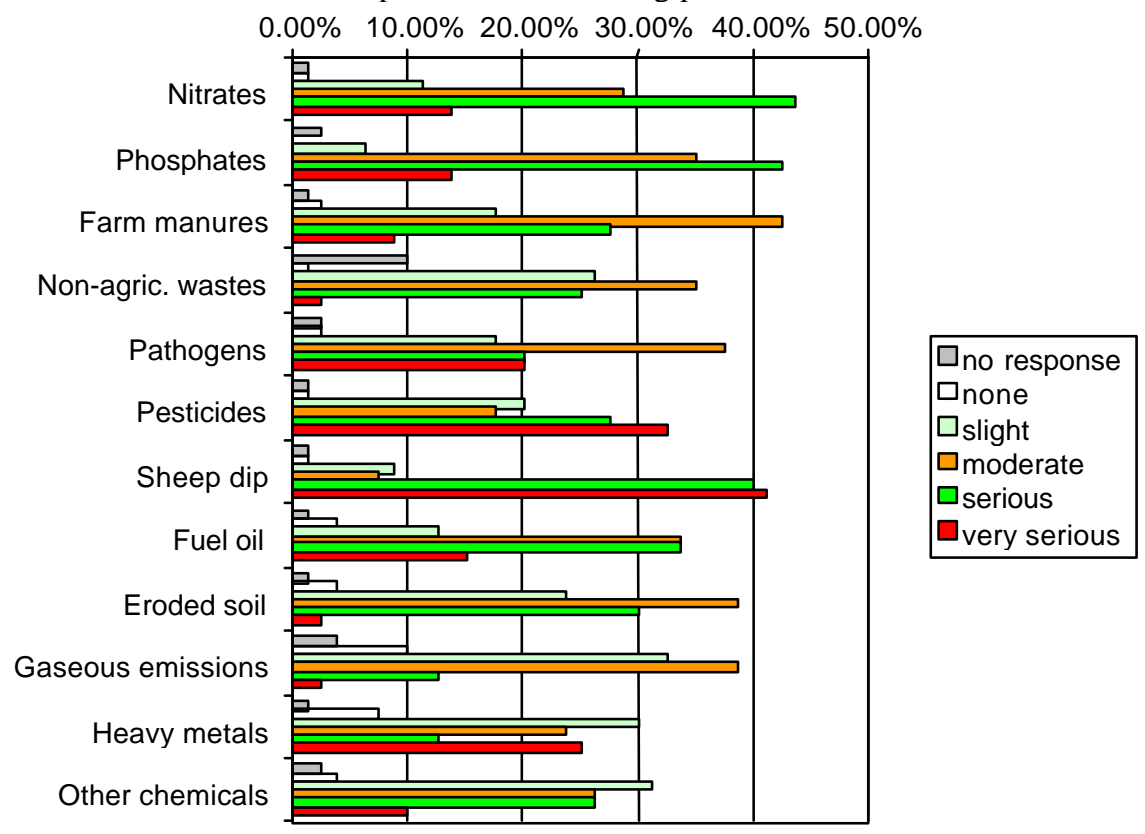

- Apart from Heavy Metals and Other Chemicals the impact on the environment of pollutants is regarded to be 'moderate' to 'very serious'.

9(a). On which of the following measures have you provided advice to farmers?

- Measures on which advice is most frequently given are Safe Disposal of Waste Sheep Dip, Manure Management, Buffer Strips, Dirty Water Management.

- Measures on which advice is least frequently given are Biobeds, Contour Ploughing, Flood Prevention, Slurry Treatment, Sprayer Selection.

9(b). Do you consider remedial measures to be effective?

- There is an overall lack of knowledge of the effectiveness of most remedial measures to reduce diffuse pollution. This must constrain advisers' delivery of advice and does indicate a high priority to increase both the level and rate of knowledge/technology transfer of research results into 'best management practices'.

10. What limits/prevents you providing advice?

- Overall, $65 \%$ of respondents felt no limitation in the provision of advice. Advisory areas with most limitation are Nutrient Planning, Biobeds, Sprayer Selection, COSHH Assessments.

- The main limitation to provision of advice is lack of knowledge followed by lack of interest from farmers.

- 23 respondents provided additional comment on reasons limiting provision of advice.

- Lack of knowledge and lack of interest often reflects the geographical area and agricultural sector in which the adviser is working. The area and/or sector may not have a range of diffuse pollution problems and no requirement to provide advice. 


\section{Training Requirements}

11. On which of the following measures do you require further information?

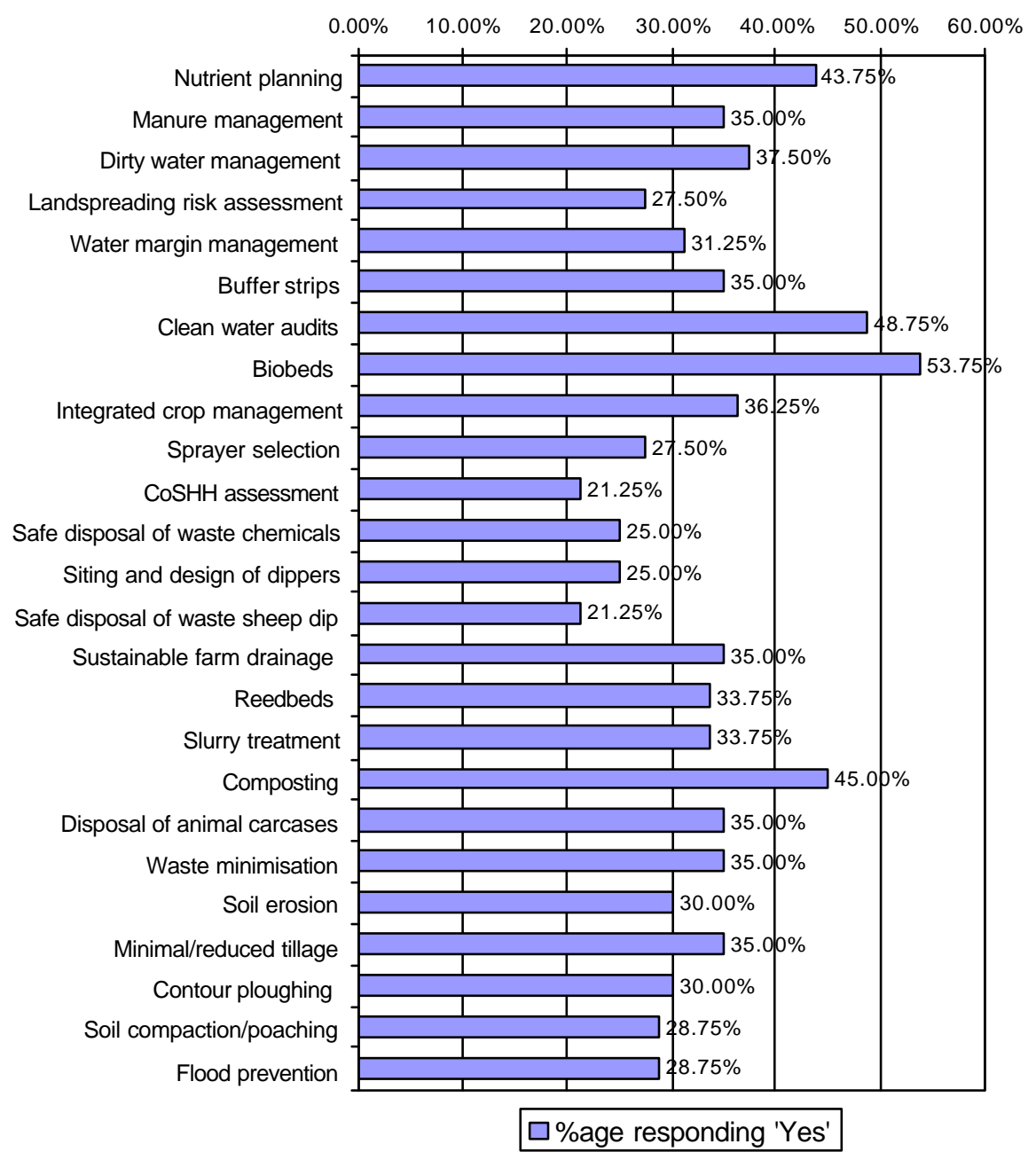

- The priority requirements for Technical Information are on Biobeds, Nutrient Planning, Clean Water Audits, Composting.

- The priority training requirements are on Nutrient Planning, Landspreading of Manures, Clean Water Audits, Sustainable Farm Drainage Systems.

12. How do you regularly keep up-to-date with environmental issues.

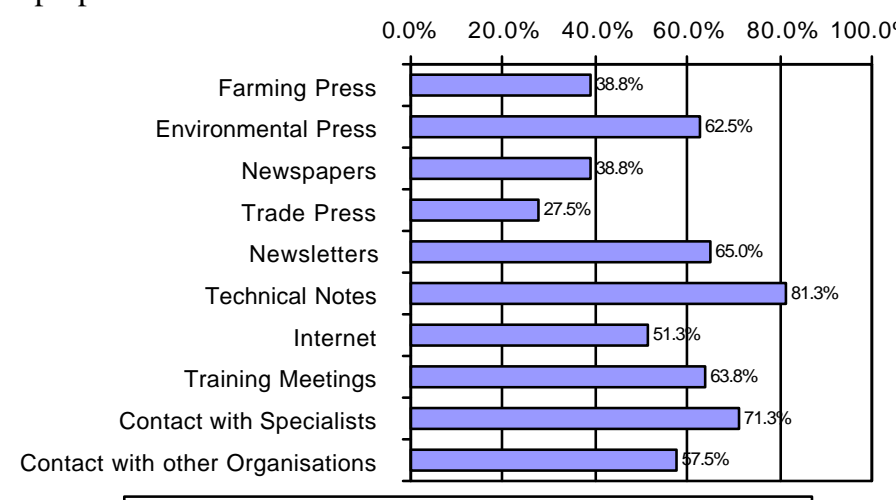

Q\%age responding 'Important' = 'very important' + 'important'

- The most commonly used sources of up-dating information are the Internet followed by Technical Notes and Specialist Contact.

- The sources regarded as being most important for providing information are Technical Notes followed by Specialist Contact and Newsletters.

- $\quad$ The sources regarded as being least important are the Trade Press, Farming Press and Newspapers. 
13. What is your preferred route for receiving technical information?

- The preferred route for receiving information is Training Courses followed by Training Manuals and Specialist Support.

- The least preferred routes are Codes of Practice and Conferences.

- Technical Notes are rated relatively low overall as respondents differed in their opinion on this route with about equal numbers rating 'high' and 'low'.

\section{Knowledge Transfer Mechanisms}

14. In your opinion, what limits/prevents Farmers adopting BMP's to minimise diffuse pollution?

- The most important limitations preventing farmers adopting BMP's are lack of funds and no appreciation of a problem.

- The least important limitations are lack of technical support and no acceptance of the problem.

15. In your opinion, how effective are each of the following for providing BMP advice to Farmers?

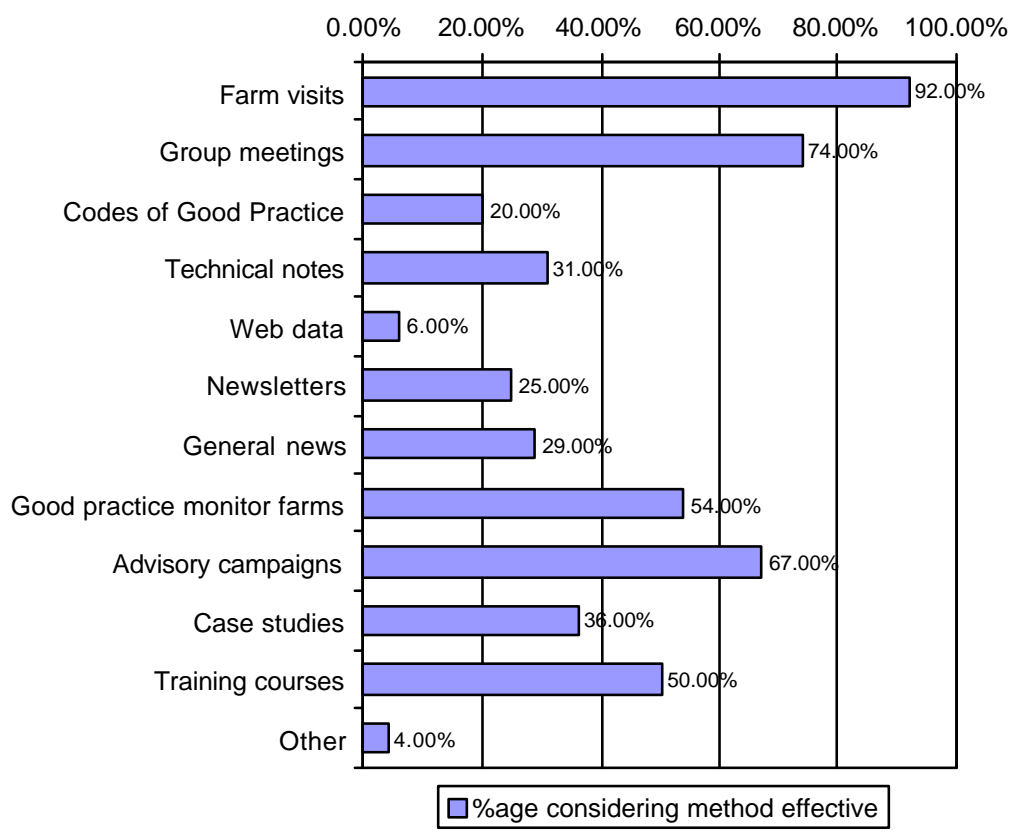

- The most effective methods of providing advice are considered to be Farm Visits (face to face) followed by Group Meetings and Advisory Campaigns.

- The least effective are considered to be Web Sites and Codes of Practice.

- Good Practice Monitor Farms were rated effective by SAC.

16. In your opinion, should environmental advice be free to all farmers?

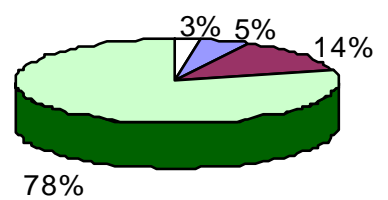

\begin{tabular}{|l|}
$\square$ no response \\
$\square$ Don't know \\
$\square$ No \\
$\square$ Yes
\end{tabular}

- The consensus of opinion is that environmental advice should be free to all farmers.

\section{CONCLUSIONS AND RECOMMENDATIONS}

- Advisers by-enlarge understand the term 'Diffuse Pollution' and rate the impact on the environment 'of some concern' or 'a serious problem'. The impact of environmental legislation on the future of the farm business is similarly rated.

- Although farmers have limited awareness of 'diffuse pollution' problems they would consider their impact on the environment to be serious.

- The pollutants rated most seriously are pesticides, nitrates, phosphates, and sheep dip.

- The most frequent requests for advice are on safe disposal of waste sheep dip, manure management, buffer strips and dirty water management.

- There is an overall lack of knowledge on the effectiveness of most remedial measures. This does constrain advisers' delivery of advice and the knowledge transfer processes. 
- The priority issues for additional advice as on nutrient planning, biobeds and sprayer selection.

- Lack of interest from farmers in some areas limits the take-up of advice.

- Lack of knowledge and/or lack of interest from farmers often reflects the geographical area and/or agricultural sector in which advice is being delivered.

- Advisers main requirement is for better technical information rather than training.

- The most commonly used sources used by advisers for new information and information update are the Internet, Technical Notes and Specialists.

- A combination of lack of funds and little appreciation of the problem limit the uptake of 'best management practices'.

- The most effective methods of knowledge transfer are Farm Visits (one-to-one advice) followed by Group Meetings and targeted Advisory Campaigns.

- There is a requirement to raise advisers' awareness of most environmental legislation, in particular the Bathing Waters Directive, the Control of Pollution Act, The Water Framework Directive, Food and Environment Protection Act, The Waste Management Licensing Regulations and the Animal By-Products Order.

- There is an urgent requirement to raise advisers' awareness of most Guidance documents to facilitate the rate of knowledge transfer to the industry. It is therefore essential that the revised PEPFAA Code is made available at an early date.

- There is an urgent requirement to increase both the level and rate of technology/knowledge transfer of research into 'best management practice' providing advisers with more reliable tools to address diffuse pollution issues.

- To improve uptake of remedial measures it is essential that advisory campaigns are directed to address catchment specific issues, i.e. targeted advice.

- Technical Notes are required on a number of issues with priority on Biobeds, Nutrient Planning, Clean Water Audits, Composting.

- Priority should be given to training on Nutrient Planning, Landspreading of Manures, Clean Water Audits, Sustainable Farm Drainage Systems.

- Environmental advice should be free to all farmers.

- Knowledge transfer should be better integrated by advisory organisations and targeted at vulnerable catchments.

- Good Practice Farms should be established to assess and demonstrate the cost-effectiveness of diffuse pollution mitigation measures.

\section{REFERENCES}

Bathing Waters Directive, 1976

BCPC, Using Pesticides: A complete guide for safe, effective spraying (1999)

Control of Pesticide Regulations, 1986

Control of Pollution (Silage, Slurry and Fuel Oil) Regulations, 2001

Control of Pollution Act, 1974

CPA, Crop Protection Management Plans (due 2002)

DEFRA/HSE, Safe Use of Pesticides on Farms and Holdings (Green Code) (1998)

DoE, Code of Practice for Agricultural Use of Sewage Sludge (1996)

Food and Environment Protection Act, 1985

Groundwater Regulations, 1998

MAFF/BOC Manual: Opportunities for Saving Money by Reducing Waste on your Farm (2002)

Nitrates Directive

Pollution Prevention and Control Regulations, 2000

SEERAD, 4 Point Plan (due 2002)

SEERAD, Guidelines for Farmers in NVZ's (due 2002)

SEERAD, PEPFAA (Revised, 2002)

SEERAD, PEPFAA Do's and Don'ts Guide, 2002

SEERAD, Sheep Dipping Code of Practice for Farmers, Crofters and Contractors (due 2002)

SEPA Soil Quality Report (2001)

SEPA, Dis posal of Waste Agrochemicals to Land. Guidance for farmers, crofters and growers (2002)

SEPA, Standard Farming Rules for Pig and Poultry PPC Installations (2002)

Sludge (Use in Agriculture) Regulations, 1989

SNH, Guidance on LERAP's (2002)

The Animal By-Products Order, 1999

The Waste Management Licensing Regulations, 1994

The Water Framework Directive, 2000

UK Water/BRC, Safe Sludge Matrix (2001)

WWF, Farming and Watercourse Management (2002) 